\title{
On Influencing Factors of the Virtual Community-based Relational Interaction on Online Shopping
}

\author{
Wan Hui \\ Wuhan Technology and Business University \\ Wuhan, China \\ 108181539@qq.com
}

\begin{abstract}
With the rapid development of Internet, the virtual community gathers a large number of netizens with its unique attraction, resulting in huge network traffic and increasing the value of the websites. Through data collection, literature analysis, hierarchical analysis model and formula analysis, this paper concludes that the core value of the research is the public praise effect of the websites, whose key influencing factor is consumer psychology, that is, consumer psychological characteristics in the virtual community. This research connects the virtual community, group behavior and online shopping together, which has certain innovation in the research perspective.
\end{abstract}

Keywords-virtual community; relational interaction; online shopping; e-commerce; influencing factor

\section{INTRODUCTION}

With the increase of Chinese netizens and the constant updating of network market, the operators of network market can no longer attract more users simply by enterprise portals because enterprise portals cannot bring more web traffic for enterprises and cannot meet netizens' diversified demands any more. The netizens' demand for network has become diversified rather than singular. Their demand no longer involves the single demand for information transmission, making friends and entertainment. Instead, it becomes more versatile, turning into a higher hierarchy of needs from a lower one. Based on the new demand, virtual communities emerge as a way for enterprises and netizens to spread and exchange information, and also satisfy the needs of online consumers. In January 2014, China Internet development statistic report shows that the usage rate of network communities in 2013 is $45 \%$ and the users reach the amount of 277.69 million, which ranks $10^{\text {th }}$ in network applications. According to the study of iResearch based on the latest netizens continuous user behavior study system iUserTracker, community dating service monthly covers 467 million people in March 2014, increasing by $7.0 \%$ compared to last year and $4.6 \%$ to February. The general permeability of community dating service in the netizens is $93.8 \%$. The stable increase of users in network communities shows that virtual community has become one of the mainstream network applications.

\section{BASIC THEORETICAL OUTLINE}

\section{A. Explanation of Related Concepts}

1) Virtual Community

The word "virtual community" was first brought up by Howard Rheingold in 1994. Howard Rheingold defined virtual community as "the social aggregation emerged in Internet", where people often discuss common topics, have emotional communication and form personal relationships.

In this paper, the relational interaction of virtual community mainly refers to the virtual community in shopping websites and the main purpose of the relational interaction is not to sell products online.

2) Relational Interaction

In this paper, the relational interaction is analyzed from the perspective of informatics. It means that the information is sent from the sender to the receiver, and the receiver absorbs, digests, processes the information and gives the corresponding feedback. In the process of sendreceive-feedback, the interactive relationship is formed, which is called the relational interaction in virtual community.

3) Online Shopping

In this paper, online shopping refers to the process of completing trades on goods, information and services between consumers and sellers through network, namely, the electronizing and networking of traditional trades.

\section{B. Analysis on Factors Influencing Online Shopping of Netizens in Virtual Community}

Netizens sharing the same interests gather around the same theme in virtual community and communicate related topics. Virtual community is not only a place for netizens to get information but also a place for emotional expression. The users of virtual community are strongly loyal.

According to the research report of 2012-2013 China online shopping user behaviour from iResearch net, factors influencing the community netizens' purchasing behaviors are: opinions from internet friends, recommendations from relatives and friends, TV ads, ads 
in Internet portals, ads in magazines, ads in newspaper and search engines' recommendations. $61.7 \%$ of the members in the virtual community consider opinions from net friends first. In virtual communities (such as BBS,BLOG), the opinion from net friends ranks first among all factors influencing purchasing behaviors.

Based on the above results, the main influencing factor on purchasing behaviors of netizens is the public praise effect and the key factor influencing the public praise effect is consumer psychology-consumer psychological characteristics in the virtual community, which include the trust between community members, interests, the sense of belonging to the community, and satisfaction with the products and brands of the community. The particularity of the virtual community emphasizes more on the inner feeling of consumers. The interpersonal interaction between members is an important way to meet the demand of the consumers.

\section{THE RELATIONAL INTERACTION'S INFLUENCE ON ONLINE SHOPPING}

\section{A. Influencing Factors}

In virtual communities, it is the consumer psychological characteristics that influence online shopping. Netizens join the virtual community for learning, getting information and satisfying their interest. Relational interaction increases the members' interest, trust, community attachment, satisfaction, loyalty and selfesteem etc. All these factors can affect online shopping. According to the theoretical and practical analysis, the relational interaction which may increase interest, trust, sense of belonging and satisfaction will exert the largest influence on online shopping.

\section{B. Modeling}

Based on the general idea of "Demand-To-Demand": the netizen's demands for learning, information transfer, group conglomeration are satisfied through the relational interaction in the virtual community, therefore, their interest, trust, sense of belonging and satisfaction will be promoted, thus generating new demand for consumption, the model is established as follows:

The variables can be explained as follows:

(1) Group culture: different groups have different values due to the differences in experience, living conditions and education levels.

(2) Information transfer: data such as pictures, texts and videos are exchanged in the online community.

(3) Learning: knowledge is acquired through network interaction.

(4) Trust: it is a subjective feeling associated with trust on the members and brands of the community.

(5) Sense of belonging: it is a subjective feeling associated with environmental identification in the community.

(6) Satisfaction: it is a subjective feeling associated with satisfaction with the community, members and brands.

(7) Online shopping: the traditional commerce is electronized, realizing the online transaction of commodity and service.

\section{MODEL ANALYSIS AND FORMULA}

\section{A. Analytical Hierarchy Process}

People's subjective choice plays a rather important role in the comparative judgment and it is difficult to quantize the significance of each factor, therefore, Saaty put forward the Analytic Hierarchy Process (AHP) in 1970. It is a systematic and hierarchical analytical method which combines qualitative and quantitative approaches. AHP is a decision-making method which decomposes the factors related to the decision-making into several layers including goals, norms and scheme, and on this basis it carries out qualitative and quantitative analysis.

\section{1) Model Representation in AHP}

a) Representation thoughts: in virtual communities, the interest-based relational interaction's impact on online shopping; the trust-based relational interaction's impact on online shopping; the sense of belonging based relational interaction's impact on online shopping and the satisfaction based relational interaction's impact on online shopping. These four variables influence online shopping at the same time, and these four variables are related to each other. We use AHP to divide the model into two layers: the upper layer is destination layer and the lower layer is criteria layer. The specific model is represented in the following diagram 3-1:

b) Comparison indications: The letters a, b, c and d are used to indicate the following four factors: interest, trust, sense of belonging and satisfaction. The importance ratio between interest-based and trust-based relational interactions is expressed as a2. The importance ratio of belonging-based relational interaction in online shopping is expressed as a3. The importance ratio of opportunity and satisfaction-based relational interaction in online shopping is expressed as a4. Successively, a matrix is obtained to indicate the influence of these four factors on online shopping and it is shown as follows:

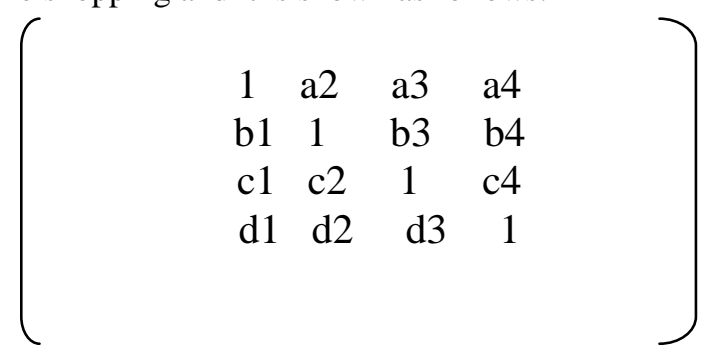

Saaty et al provide nine scales: $1,2, \ldots, 9$ and their reciprocals: $1,1 / 2, \ldots, 1 / 9$. Therefore, all numbers in the matrix are between one and nine. The meanings of these numbers are expressed in Table 1.

c) Characteristic values and weights: The characteristic values of Matrix A are calculated. W is used to show the eigenvector matrix of the largest characteristic 
value. The transposition of eigenvector $\mathrm{W}$ is the weight vector required in this paper, which is expressed as $\mathrm{WT}=(\mathrm{w} 1 \mathrm{w} 2 \mathrm{w} 3 \mathrm{w} 4)$.

d) Consistency check: It is a data checkout which involves the reliability and validity of the check results. There may be the following two cases:

Complete consistency: in this case, all the mutual proportions of these four factors are 1 and the weight vector $\mathrm{W}^{\mathrm{T}}=(\mathrm{w} 1 \mathrm{w} 2 \mathrm{w} 3 \mathrm{w} 4)=1$.

Incomplete consistency: Consistency is verified according to the index: $\mathrm{CI}=(\lambda-n) /(n-1)$, in which $\lambda$ represents the largest characteristic value. A larger CI value indicates a more obvious inconsistency. We usually introduce random coincidence indicator RI, which is obtained through table look-up. The corresponding values are shown in Table 2.

Then the RI value is used in the formula to calculate $\mathrm{CI}$, thus $\mathrm{CR}$, because the consistency ratio is defined as: $\mathrm{CR}=\mathrm{CI} / \mathrm{RI}$. When $\mathrm{CR}<0.1$, consistency checkout is validated and if $C R>0.1$, the data needs adjustment.

\section{2) Analysis on Hypothetical Data}

In virtual communities, according to most people's intention: the ratio of the interest-based relational interaction's impact on online shopping intention and online shopping is the largest among all factors; besides, the trust-based relational interaction's effect on online shopping intention and times is also great; the relational interaction based on the satisfaction degree has smaller impact on online shopping, and the relational interaction based on the sense of belonging affects the online shopping least among all variables.

According to the intention of most members, the following matrix $\mathrm{A}$ is obtained.

$$
A=\left[\begin{array}{cccc}
1 & 2 & 6 & 5 \\
1 / 2 & 1 & 4 & 3 \\
1 / 6 & 1 / 4 & 1 & 2 \\
1 / 5 & 1 / 3 & 1 / 2 & 1
\end{array}\right]
$$

Calculated with MATLAB software, the maximum characteristic value $\lambda$ is 4.1172 .

The consistency checking result $\mathrm{CR}=$ $\mathrm{CI} / \mathrm{RI}=0.0434<0.1$ indicates that the consistently of the data results is verified.

The corresponding feature vector of $\lambda$ is WT $=$ $\left(\begin{array}{llll}0.8492 & 0.4820 & 0.1695 & 0.1332\end{array}\right)$

The corresponding feature vector of $\lambda$ is weight vector, and we normalize the weight vector to get a weight $\mathrm{V}=\left(\begin{array}{llll}0.5198 & 0.2950 & 0.1037 & 0.0815\end{array}\right)$. We substitute the weight to get the model representation, shown in figure 3-2.

Figure 3-2 shows that in a large community, people gather together based on various demands. Interest plays the biggest role in this aggregation. Interest is always the focus. Therefore, in the model weight structure diagram, the interest's influence on online shopping is the greatest, accounting for 0.5198 , followed by the trust among community members. By contrast, the impact of the sense of belonging tends to be smaller because the sense of belonging in virtual communities is often based on shortterm interests.

\section{EFFECTIVE APPLICATION OF RELATIONAL INTERACTION IN VIRTUAL COMMUNITY BY THE COMSUMERS AND ENTERPRISES}

\section{A. Effective Applications by Consumers}

\section{1) Obtaining Information Effectively}

The consumers can look for their required information and knowledge in the relevant communities and groups according to their own interest and demand. They can also communicate with people who have the same interest to meet their own requirements.

2) Obtaining Better Community Experience

The enterprises can make better use of the netizens' relational interaction to launch better activities, thus satisfying their demand more effectively. In the end, the netizens will get the most benefit from it because online shopping is no longer a simple activity, instead, it will become a better experience and enjoyment. Even if community members have no intentions to shop online, they can still make friends, acquire knowledge, let off bad emotions and seek comfort in the community. As a result, their sense of experience will be promoted imperceptibly.

\section{B. Effective Applications by Enterprises}

The enterprises can make use of the convergence \& divergence feature of the community and search out their consumers' interests, hobbies according to the positioning analysis of their own products and services, thus carrying out targeted network marketing in the community. In addition, the enterprises can also analyze the relational interaction among the consumers in the virtual community. In the interaction, the scattered information is gathered, managed and analyzed. In the constant information feedback, the enterprises can analyze the customer demands, customer resources value and customer delivered value to seek new marketing opportunities. The community cohesion helps the enterprises to have more accurate orientation, making their marketing more accurate and focused.

\section{REFERENCES}

[1] Yao Xiuli. Consumer Behavior and Online Shopping [M]. Beijing: Science Press, 2010.

[2] Zhu Min, Zhang Mingxing. Establishment of Research System of Public Praise and Measurement Model Research [M]. Beijing: Science Press, 2011.

[3] Michael R.Solomon, Lu Taihong, Yang Xiaoyan, trans by Hao Jia, Hu Xiaohong, Zhang Hong Ming. Consumer Behavior [M]. Beijing: China Renmin University Press, 2014.

[4] Lei Jing, Knowledge Sharing Research Based on the Virtual Community of Social Network [D]. Shanghai: Donghua University, 2012: 24-32. 
[5] Wang Dongju. Online Consumer Behavioral Modeling [D]. Guangdong: Wuyi University, 2012: 35-62.

[6] Wang Quanhe. Fuzzy Inference Research on the Purchase Intention of Online Consumer [D]. Dalian: Dalian University of Technology, 2013: 43-51.

[7] Cai Jikang. Research on the Value Reception Model for the Consumers in the Transactional Virtual Community[D]. Qingdao: Ocean University of China, 2013: 18-25.
[8] Xiao Daibo. Reversed Intergeneration Impact of Consuming Behavior[J]. Wuhan: Wuhan University, 2013: 23-36.

[9] Wang Yanmei, Yu Weiping. Multi-dimensional Perspective Comparison and Value Analysis for the Interaction of Virtual Community[J]. Library Research, 2010,12 (1): 3-7.

[10] Su Zhaohui. Customer Relation Management: Idea, Techniques and Strtegies[M]. Beijing: China Machine Press, 2013.

[11] Zhou Sanduo, Chen Chuanming, Lu Minghong. Principles of Management[M]. Shanghai: Fudan University Press, 2011.

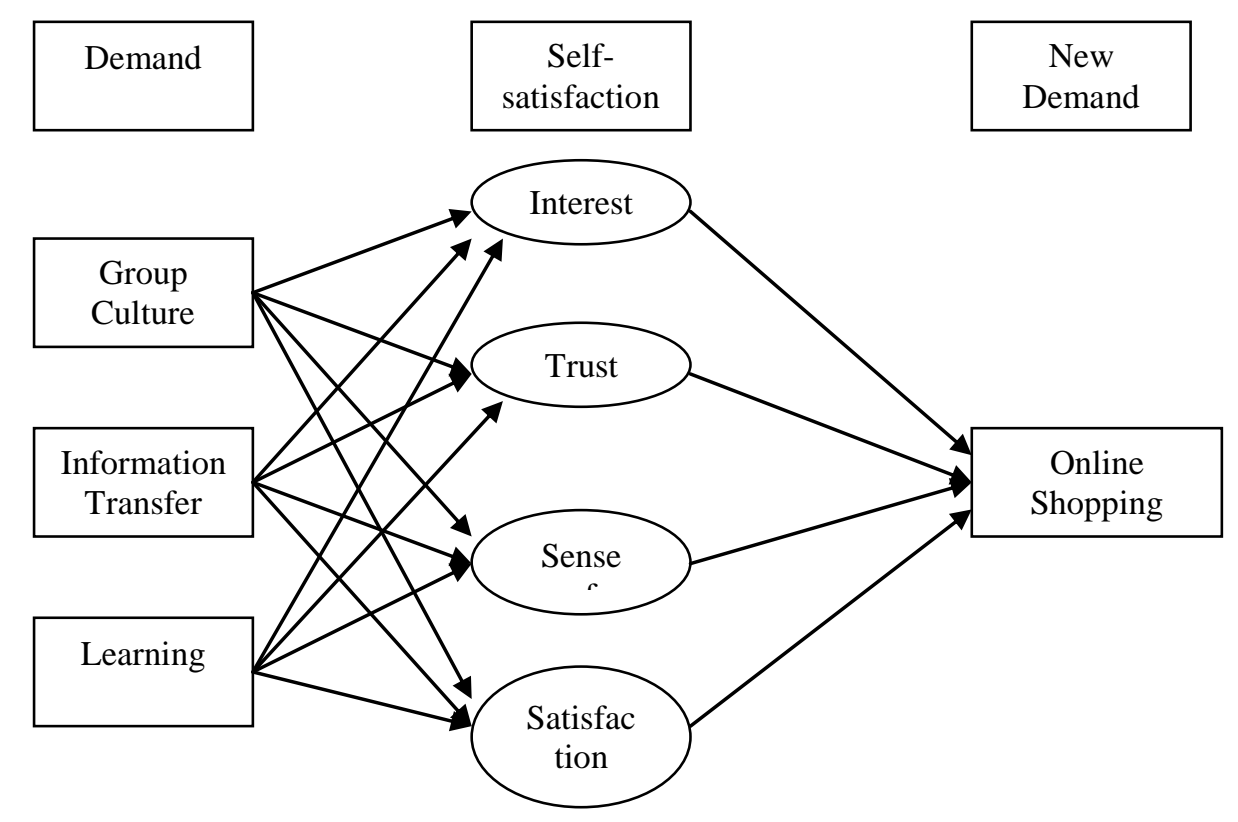

Figure 2-1 Demand-To-Demand Model

Destination Layer:

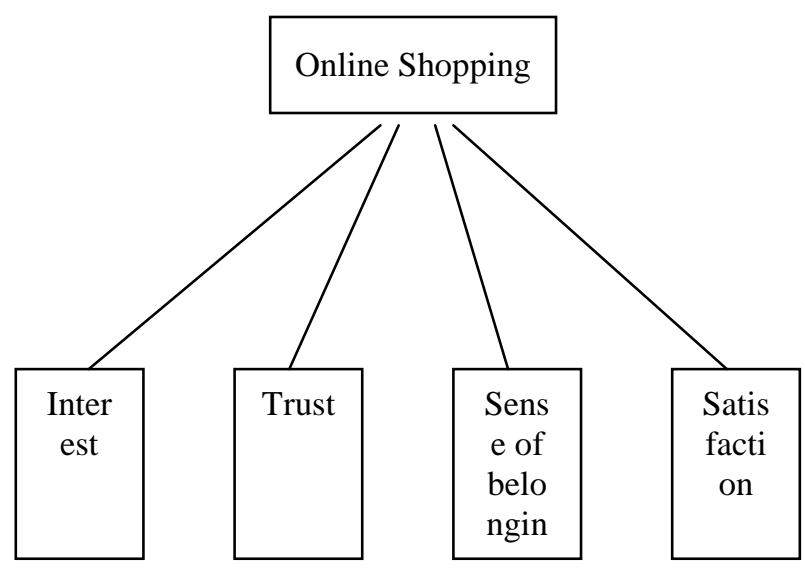

Criteria Layer

Figure 3-1 Destination Layer and Criteria Layer of the Model

TABLE I

\begin{tabular}{|c|c|c|c|c|c|c|c|c|c|}
\hline Scale & 1 & 2 & 3 & 4 & 5 & 6 & 7 & 8 & 9 \\
\hline Significance & \multicolumn{8}{c|}{ same } & slightly strong \\
\hline
\end{tabular}


TABLE 2:

\begin{tabular}{|c|c|c|c|c|c|c|c|c|c|c|c|}
\hline $\mathrm{n}$ & 1 & 2 & 3 & 4 & 5 & 6 & 7 & 8 & 9 & 10 & 11 \\
\hline $\mathrm{RI}$ & 0 & 0 & 0.58 & 0.90 & 1.12 & 1.24 & 1.32 & 1.41 & 1.45 & 1.49 & 1.51 \\
\hline
\end{tabular}

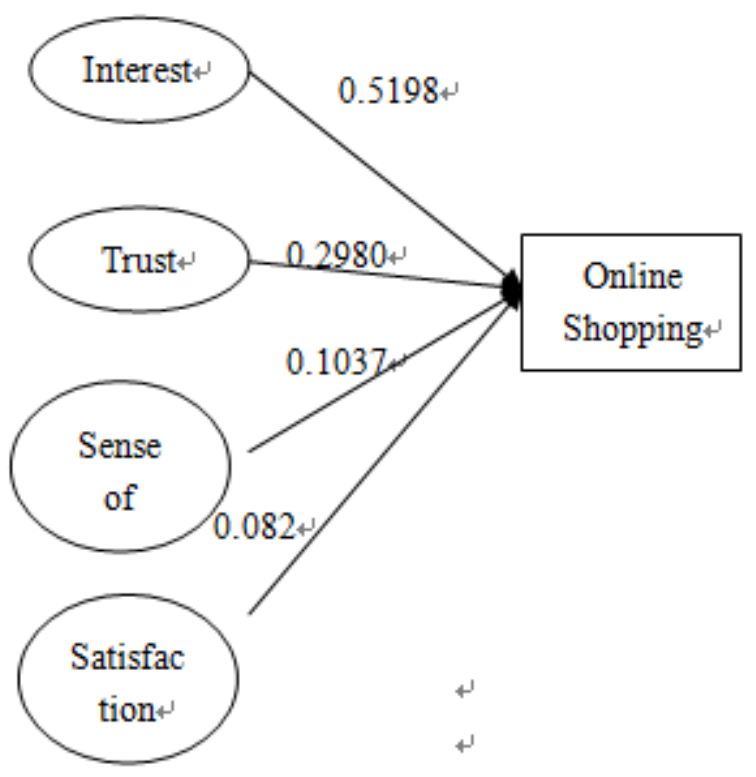

Figure 3-2 Model Weight Results 